\title{
Cystichygroma with Macroglossia-A Lymphatic Malformation in a Neonate
}

\section{Venkateshlyer Harohalli*}

Consultant Neonatologist, Manipal Hospital, Bangalore

\section{Introduction}

This 15 days old male infant born at 38 weeks of gestation by spontaneous vaginal delivery was brought to paediatric emergency room with the history of hurried breathing and poor feeding and swelling in the neck (Figure 1). Clinical diagnosis of cystic hygroma with air way compromise was made. Antenatal scans done were normal. In view of deteriorating respiratory distress the child was ventilated. X-ray of neck showed mass on either side of the neck (Figure 2). Ultrasound demonstrated bilateral cystic areas consistent with cystic hygroma

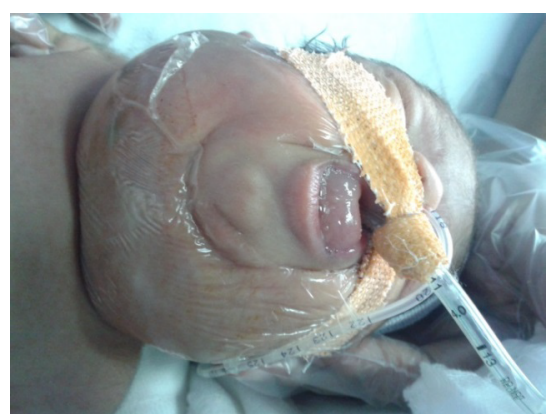

Figure 1: A new born with cystic hygroma with macroglossia.

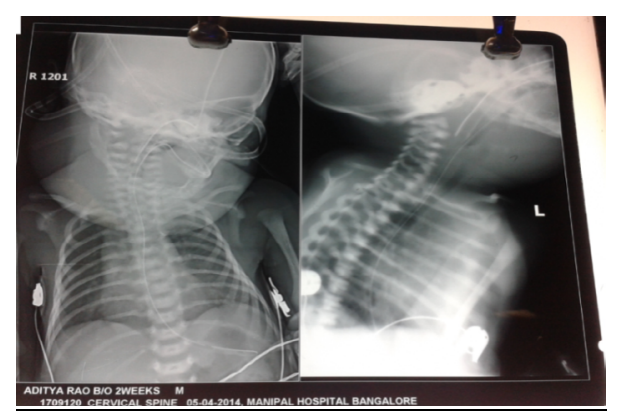

Figure 2: X-ray neck showing bilateral mass in the neck.

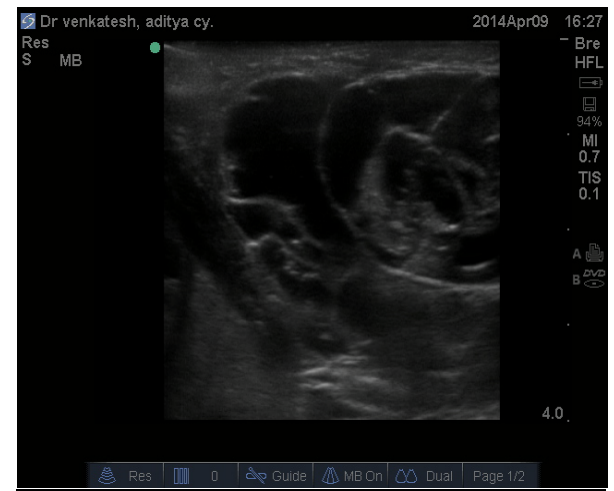

(multicystic) (Figure 3). CT neck wasdone to rule out any thoracic extension (Figure 4). The mass was infiltrated with sclerosant OK 432 (FDA approved) under ultrasound.

\section{Discussion}

Cystic hygroma a lateral neck mass is a shocking scene for any parents. Air way compromise is the major threat to the baby. Early recognition, respiratory care, timelysclerosant therapy, surgery in selected candidates and adequate informative counselling are the main challenges for the treating physician.

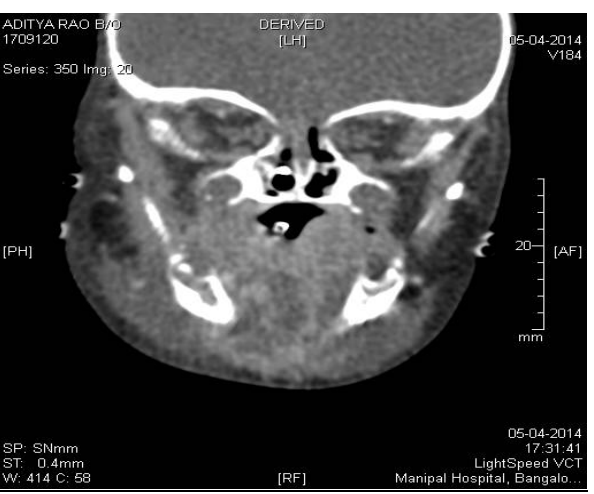

Figure 4: C T neck showing cystic hygroma bilateral.

*Corresponding author: Venkateshlyer Harohalli, Consultant Neonatologist Manipal Hospital, Bangalore, India, Tel: 919980135300; E-mail Venkatveena46@gmail.com

Received May 29, 2014; Accepted May 31, 2014; Published June 02, 2014

Citation: Harohalli V (2014) Cystichygroma with Macroglossia-A Lymphatic Malformation in a Neonate. J Neonatal Biol 3: 145. doi:10.4172/2167-0897.1000145

Copyright: (c) 2014 Harohalli V. This is an open-access article distributed under the terms of the Creative Commons Attribution License, which permits unrestricted use, distribution, and reproduction in any medium, provided the original author and

Figure 3: Ultrasound neck showing cystic hygroma. 